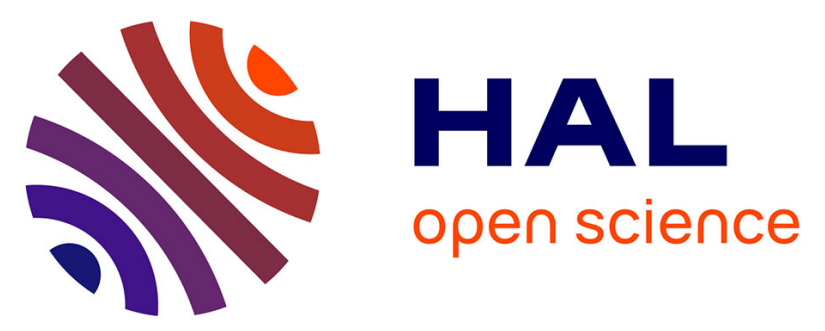

\title{
SMARCB1/INI1 inactivation in renal medullary carcinoma
}

Julien Calderaro, Julien Moroch, Gaelle Pierron, Florence Pedeutour, Camille Grison, Pascale Maillé, Pascale Soyeux, Alexandre de La Taille, Jérome

Couturier, Annick Vieillefond, et al.

\section{To cite this version:}

Julien Calderaro, Julien Moroch, Gaelle Pierron, Florence Pedeutour, Camille Grison, et al.. SMARCB1/INI1 inactivation in renal medullary carcinoma. Histopathology, 2012, 61 (3), pp.42835. 10.1111/j.1365-2559.2012.04228.x . hal-03329097

\section{HAL Id: hal-03329097 https://univ-angers.hal.science/hal-03329097}

Submitted on 30 Aug 2021

HAL is a multi-disciplinary open access archive for the deposit and dissemination of scientific research documents, whether they are published or not. The documents may come from teaching and research institutions in France or abroad, or from public or private research centers.
L'archive ouverte pluridisciplinaire HAL, est destinée au dépôt et à la diffusion de documents scientifiques de niveau recherche, publiés ou non, émanant des établissements d'enseignement et de recherche français ou étrangers, des laboratoires publics ou privés. 


\section{SMARCB1/IN/1 inactivation in renal medullary carcinoma}

Julien Calderaro, ${ }^{1}$ Julien Moroch, ${ }^{1}$ Gaelle Pierron, ${ }^{2}$ Florence Pedeutour, ${ }^{3}$ Camille Grison, ${ }^{2}$ Pascale Maillé, ${ }^{1}$ Pascale Soyeux, ${ }^{4,5}$ Alexandre de la Taille, ${ }^{4,5,6}$ Jérome Couturier, ${ }^{2}$ Annick Vieillefond, ${ }^{7}$ Marie Christine Rousselet, ${ }^{8}$ Olivier Delattre ${ }^{2}$ \& Yves Allory ${ }^{1,4,5}$ ${ }^{1}$ AP-HP, Département de Pathologie, Hôpital H. Mondor - A. Chenevier, Créteil, ${ }^{2}$ Unité de Cytogénétique et Génétique Somatique, Institut Curie, Paris, ${ }^{3}$ Unité de Génétique des Tumeurs Solides, Université de Nice-Sophia-Antipolis et Centre Hospitalier Universitaire de Nice, Nice, ${ }^{4}$ Inserm, U955, Créteil, ${ }^{5}$ Faculté de médecine, Université Paris Est, Créteil, ${ }^{6}$ APHP, Service d'Urologie, Hôpital H. Mondor - A. Chenevier, Créteil, ${ }^{7}$ AP-HP, Département de Pathologie, Hôpital Cochin, Paris, and ${ }^{8}$ Département de Pathologie Cellulaire et Tissulaire, Centre Hospitalier Universitaire, Angers, France

Date of submission 24 July 2011

Accepted for publication 4 December 2011

Calderaro J, Moroch J, Pierron G, Pedeutour F, Grison C, Maillé P, Soyeux P, de la Taille A, Couturier J, Vieillefond A, Rousselet M C, Delattre O \& Allory Y

(2012) Histopathology

\section{SMARCB1/INI1 inactivation in renal medullary carcinoma}

Aims: Renal medullary carcinoma (RMC), a rare and highly aggressive tumour which occurs in patients with sickle-cell disease, shares many clinicopathological features with collecting duct carcinoma (CDC). The molecular mechanisms underlying RMC and CDC are mainly unknown, and there is ongoing debate about their status as distinct entities. Loss of expression of SMARCB1/INI1, a chromatin remodelling regulator and repressor of cyclin D1 transcription, has been reported recently in RMC. The aim of our study was to investigate if such loss of expression is specific for RMC. SMARCB1/INI1 genetic alterations and cyclin D1 expression were also studied.
Methods and results: Using immunochemistry, neoplastic cells showed complete loss of SMARCB1/INI1 expression in all six cases of RMC but in only one of 22 cases of CDC. In two RMC cases investigated, comparative genomic hybridization demonstrated complete loss of one SMARCB1/INI1 allele, with no other genomic imbalances, and no mutations were found on the remaining allele. Cyclin D1 was expressed in all RMCs, suggesting that SMARCB1/INI1 inactivation may result in increased cyclin D1 transcription.

Conclusions: The specific SMARCB1/INI1 inactivation observed in RMCs suggests that RMC and CDC are different entities.

Keywords: collecting duct renal cell carcinoma, cyclin D1, INI1, renal medullary carcinoma, rhabdoid, sickle cell disease

Abbreviations: ALK, anaplastic lymphoma kinase; CDC, collecting duct carcinoma; CGH, comparative genomic hybridization; FISH, fluorescence in-situ hybridization; INI1, integrase interactor 1; RMC, renal medullary carcinoma; SMARCB1, SWI/SNF-related, matrix-associated, actin-dependent regulator of chromatin, subfamily B, member 1

\section{Introduction}

Renal medullary carcinoma (RMC) is a rare and highly aggressive tumour which occurs in young patients or

Address for correspondence: Professor Y Allory, Département de Pathologie-CHU Henri Mondor, 51 Avenue du Maréchal de Lattre de Tassigny, 94000 Creteil, France. e-mail: yves.allory@hmn.aphp.fr children with sickle cell trait or disease. ${ }^{1-3}$ It resists most conventional chemotherapeutic agents, and metastases are most often present at diagnosis. ${ }^{1-3}$ The prognosis of patients with RMC is very poor, and the diagnosis is virtually always associated with a lethal outcome within months. ${ }^{1-3}$ Microscopically, $\mathrm{RMC}$ is a poorly differentiated carcinoma, most often consisting of solid or cribriform cell clusters. ${ }^{1,3,4}$ 
Tubules, microcysts, and reticular or sarcomatoid areas may also be observed. Tumour cells have a large, highly atypical nucleus and dense eosinophilic cytoplasm; an eccentric nuclear displacement may focally create a rhabdoid appearance. ${ }^{1}$ Stroma is usually fibrotic and contains numerous inflammatory cells. ${ }^{1,3,4}$ As its clinical and pathological features strongly resemble those of collecting duct carcinoma (CDC), the existence of RMC as a separate entity is debated and some consider it a variant of CDC. ${ }^{5,6}$

Due to its rarity, molecular mechanisms underlying RMC development are unknown. Amplification of $A B L$ (Abelson murine leukaemia viral oncogene homologue 1 ) and ALK (anaplastic lymphoma kinase) rearrangement have been reported in isolated cases. ${ }^{7,8}$ Comparative genomic hybridization (CGH) has demonstrated loss of chromosome 22 in one of nine RMC cases, the remaining cases showing lack of genetic gains or losses. $^{9}$

Recently, an immunohistochemical study reported lack of nuclear integrase interactor 1 (INI1) expression in five cases of RMC. ${ }^{4}$ The tumour supressor INI1, also called SMARCB1 (SWI/SNF-related, matrix-associated, actin-dependent regulator of chromatin, subfamily B, member 1) is located on 22q11.23, and encodes a component of the ubiquitous SWI/SNF complex. ${ }^{10}$ This adenosine triphosphate (ATP)-dependent epigenetic complex regulates transcription of numerous target genes by modulating access of the transcriptional machinery to DNA sequences. ${ }^{10,11}$ SWI/SNF is required for numerous cell processes, including cell cycle checkpoint control and differentiation. ${ }^{10,12}$ Loss of SMARCB1/INI1 expression, which leads to increased cyclin D1 expression, ${ }^{13,14}$ has been described in paediatric renal and extrarenal malignant rhabdoid tumours, atypical teratoid/rhabdoid tumours of the central nervous system and epithelioid sarcomas, ${ }^{15-20}$ and patients with germline alterations of $S M A R C B 1 / I N I 1$ are predisposed to malignant rhabdoid tumours. ${ }^{21,22}$ So far, SMARCB1/INI1 molecular alterations have comprised deletions, mutations and/or epigenetic silencing by DNA methylation. ${ }^{10,23-25}$ In RMC, the molecular alterations underlying loss of INI1 expression have yet to be investigated.

To determine if both CDC and RMC share loss of SMARCB1/INI1 expression, we studied SMARCB1/ INI1 by immunohistochemistry in six cases of RMC and 22 cases of CDC. CGH array and sequencing of SMARCB1/INI1 9 exons could be performed in two cases of RMC to investigate the underlying molecular mechanisms that may be involved in SMARCB1/INI1 inactivation.

\section{Material and methods}

\section{TISSUE SPECIMENS}

Six cases of RMC and 22 cases of CDC diagnosed between 1991 and 2010 were retrieved from the archives of the Pathology Departments of Henri Mondor Hospital (Creteil), Cochin Hospital (Paris) and University Hospital (Angers), France; four of six RMCs were second-opinion consultation cases. For all cases, haematoxylin and eosin-safran slides and paraffin blocks were available. Frozen samples were available for two cases.

\section{PATIENTS}

Mean age at diagnosis was 33.5 years (age range 2545 years) for patients with RMC and 61 years (age range 43-82 years) for patients with CDC. Sex ratios (male/female) were 2 and 4.2 for patients with RMC and $\mathrm{CDC}$, respectively. According to French ethical laws, we confirmed that no patient was opposed to the study.

\section{IMMUNOHISTOCHEMISTRY}

For SMARCB1/INI1 immunostaining, after deparaffinization and inhibition of endogenous peroxidase, the sections were placed into high $\mathrm{pH}$ target retrieval solution (Dako/Cytomation, Carpinteria, CA, USA) and microwaved for antigen retrieval. Sections were incubated with a primary mouse monoclonal antibody against SMARCB1/INI1 (BD Transduction Laboratories, San Diego, CA, USA; dilution 1:50) for $1 \mathrm{~h}$ at room temperature, and washed with phosphate-buffered saline solution. After incubation with the Envision+ System labelled polymer-horseradish peroxidase (HRP) kit (Dako/Cytomation) and staining with 3'-diaminobenzidine (Dako) as chromogen, the slides were counterstained with Mayer's haematoxylin, dehydrated and coverslipped. For cyclin D1 (clone SP4, dilution 1:25; Thermo Scientific, Wilmington, DE, USA) and ALK (DakoCytomation; clone ALK1, dilution 1:20) immunostaining, paraffin sections were processed on an automated instrument (Bond Max; Leica Microsystems, Wetzlar, Germany), according to the manufacturer's instructions.

\section{SMARCB1/INI1 SEQUENCING}

Tumoral DNAs were extracted from snap-frozen tumours with the phenol-chloroform method using Phase Lock Gel (5PRIME, Gaithersburg, MD, USA). 
They were quantified and qualified using Nanodrop ${ }^{\circledR}$ (Thermo Scientific) and Qubit ${ }^{\circledR}$ (Invitrogen, Carlsbad, CA, USA). For the analysis and sequencing of genomic DNA, primer couples located in introns and amplifying the nine exons of SMARCB1/INI1 were designed (1 forward CTTCCGGCTTCGGTTTCCCT, 1 reverse GAT GAATGGAGACGCGCGCT; 2 forward GTTGCTTGATG CAGTCTGCG, 2 reverse TTCATGACATAAGCGAGTGG; 3 forward AGGCCAGCATTCAGCAGTAG, 3 reverse CCACAGGTGTCCCCAGAGAT; 4 forward CCCTGGAGC ATTAGTTGATT, 4 reverse GAACTAAGGCGGAAT CAGCA; 5 forward CTCGCTGACTGTTGCTTCC, 5 reverse CAACCTCAGTATGGGGAAAG; 6 forward AA GCATGGTGCAATCTCTTGG, 6 reverse CCTTGGTGTA CCCTCAGTGC; 7 forward ACAAGGACCACCTGCA GTTC, 7 reverse AAGCCTCAAAGGTATCACCG; 8 forward GGCCAAAGCTTTCTGAGGAT, 8 reverse CATGG GAGACTGGGAAAGGC; and 9 forward TGTTCCCACC CCTACACTTG, 9 reverse GCAGGACTGGGGCTCAAC).

Polymerase chain reaction (PCR) products were purified and sequenced bidirectionally using the Big Dye terminator version 1.1 kit (Applied Biosystems, Foster City, CA, USA) on automatic 3100 sequencers. Sequences were analysed by SeqScape software. A multiplex ligation-dependent probe amplification (MLPA) approach investigating the nine exons of the SMARCB1/INI1 gene was used to detect whole gene or intragenic deletions (SALSA MLPA kit P258 SMARCB1; MRC Holland, Amsterdam, the Netherlands; following the manufacturer's instructions).

\section{ARRAY CGH}

The samples were labelled and co-hybridized on a NimbleGen Human CGH $3 \times 720 \mathrm{~K}$ whole-genome tiling array (Hg18; NCBI36) with a median probe spacing of 2509 base pairs (bp), following the manufacturer's instructions. Arrays were washed and then scanned on a GenePix 4000B Scanner using GenePix version 6.0 software (AXON/Molecular Devices, Sunnyvale, CA, USA). Raw data were normalized and processed using the segMNT algorithm NimbleScan version 2.5 software (Roche NimbleGen, Madison, WI, USA) to obtain data with a resolution of $100 \mathrm{bp}$ (average of nine features). Analysis and visualization were performed with SignalMap version 1.9 (Roche NimbleGen).

\section{FLUORESCENCE IN-SITU HYBRIDIZATION (FISH)}

Five- $\mu$ m-thick sections of the formalin-fixed, paraffinembedded tissues on silanized slides were deparaffinized for $3 \times 10 \mathrm{~min}$ in xylene, washed in 100\% ethanol, airdried and incubated with pepsin, using the Histology
FISH Accessory kit (Dako, Glostrup, Denmark) according to the manufacturer's instructions. For each slide, $200 \mathrm{ng}$ of the digoxigenin-labelled bacterial artificial chromosome (BAC) probes RP11-71G19 containing the SMARCB1/INI1 gene at 22q11.23 and RP11-262A13 at 22q13.32 (used as an internal control) (http:// genome.ucsc.edu/) were hybridized according to standard FISH procedures. The EWSR1 probe (22q12) from Abbott Molecular (Desplaines, IL, USA) was used according to the manufacturer's instructions. A minimum of 100 nuclei were visualized per slide. For each nucleus analysed, the numbers of fluorescent red and green signals were evaluated. Microscopic analysis was performed using a DM6000B microscope (Leica Microsystems). FISH images were processed using ISIS software (MetaSystems, Altussheim, Germany).

\section{Results}

\section{MICROSCOPIC FEATURES}

Microscopic examination of all cases of RMC showed an infiltrative and poorly differentiated carcinoma consisting of solid or cribriform cell clusters (Figure 1A), with few areas of rhabdoid de-differentiation (Figure 1B). The stroma was fibrotic and featured numerous inflammatory cells. Sickle cell erythrocytes could be identified in three of six cases. In cases of CDC, which also featured poorly differentiated areas but no rhabdoid de-differentiation, the architectural pattern was cribriform, tubular or focally tubulopapillary (Figure 1C). Foci of spindle cells and microcysts were also observed. Stroma was desmoplastic and fibro-inflammatory.

\section{IMMUNOHISTOCHEMISTRY}

For the six cases of RMC, SMARCB1/INI1 immunostaining was negative in all tumour cells (Figure 1D). Inflammatory and stromal cells provided an internal positive control with moderate to strong nuclear immunostaining (Figure 1D). Twenty-one of 22 CDCs showed positive nuclear immunostaining of tumour cells (Figure 1E). Of note, in cases of RMC and CDC, adjacent non-tumoral collecting duct cells were strongly positive (Figure 1F). Nuclear expression of cyclin D1 was observed in all RMCs, with intensity ranging from mild to strong (Figure 1G). ALK expression was not detected in any RMC cases (Figure 1H).

ARRAY CGH, FISH AND SMARCBI/INII SEQUENCING

For two of six RMC cases, high-resolution CGH experiments were performed and showed loss of one 


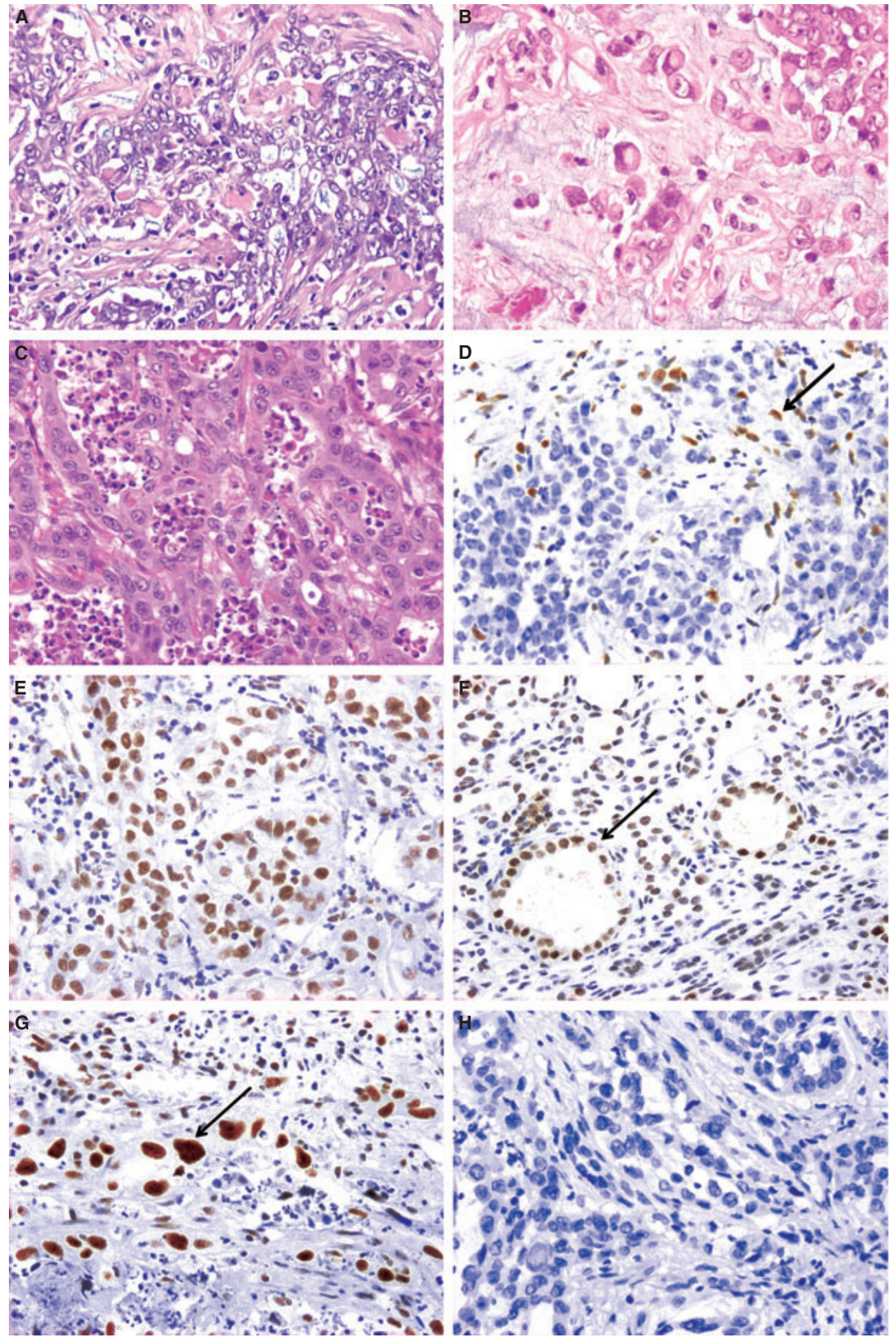

Figure 1. Morphological and immunohistochemical features of renal medullary carcinoma (RMC) and collecting duct carcinoma (CDC). A, RMC with reticular and cribriform pattern. B, Focal rhabdoid features with eccentric nuclei in RMC. C, CDC with tubular and cribriform pattern similar to RMC. D, Absence of SMARCB1/INI1 expression in RMC neoplastic cells. Note the positive nuclear immunostaining in stromal and inflammatory cells (arrow). E, Nuclear SMARCB1 / INI1 expression in CDC neoplastic cells. F, Renal tubular epithelial cells with SMARCB1 / INI1 expression (arrow) adjacent to case of RMC. G, Strong cyclin D1 nuclear expression in neoplastic cells of RMC (arrow). H, Lack of anaplastic lymphoma kinase expression in neoplastic cells of RMC. 
A

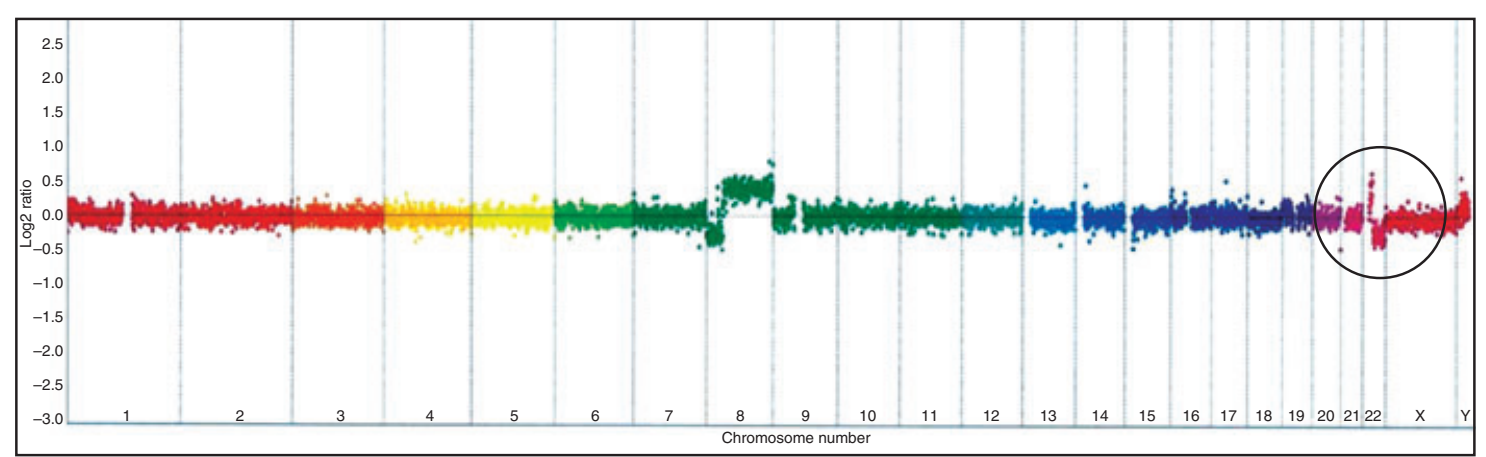

B

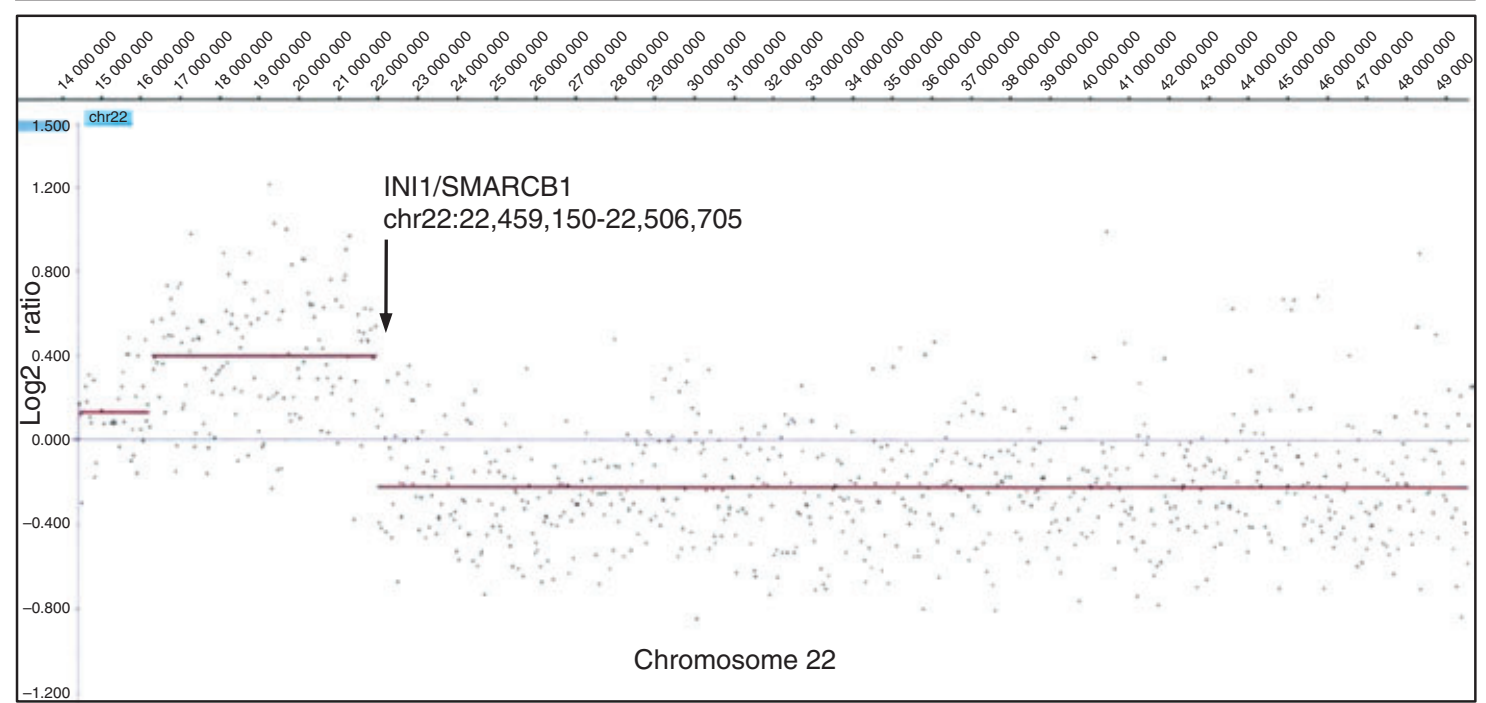

C

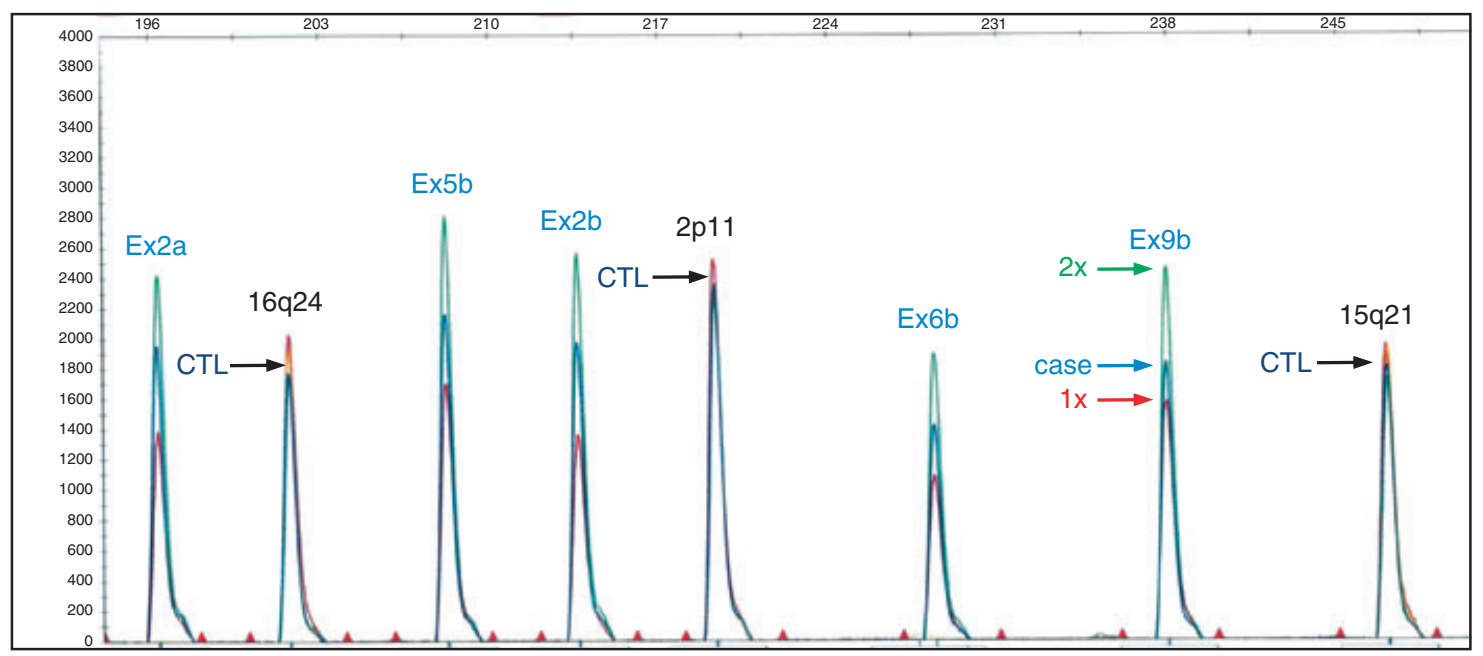

Figure 2. SMARCB1 / INI1 locus deletion in case 1. A, Whole genome array CGH highlighting a distal 22q deletion. B, Zoom-in on chromosome 22 showing a small gain of 22q proximally, a breakpoint occuring near the SMARCB1/INI1 locus and the loss of the distal part of 22q. Due to the presence of $20 \%$ non-tumour cells in the sample, a small shift between $\times 1$ copy and the case was observed. C, Validation of the hemizygous deletion by multiplex ligation-dependent probe amplification (MLPA). The sample case 1 (blue) and two control samples are aligned (normal reference in green, control with only one copy of SMARCB1/INI1 in red). Samples are calibrated on control peaks located on chromosomes 2, 15 and 16 (black arrows). Then, for each exon (two amplifications a and b), the copy number of the case is estimated in relation to the $\times 2$ and $\times 1$ controls (blue, green and red arrows, respectively), confirming hemizygous deletion of all $S M A R C B 1 / I N I$ exons. 
allele of the SMARCB1/INI1 gene (Figure 2). In case 1 there was a distal loss of chromosome 22q (Figure 2A,B), which was validated by MLPA assay showing a hemizygous deletion of SMARCB1/INI1 with the loss of all exons (Figure 2C). Only one other chromosomal rearrangement, iso8q, resulting in a loss of $8 \mathrm{p}$ and a gain of $8 \mathrm{q}$, was observed for this case (Figure 2A). Zooming-in on chromosome 22, a small gain of the proximal part of $22 \mathrm{q}$ was detected just before the breakpoint occurring near the SMARCB1/ INI1 locus (Figure 2B). This result was confirmed by a FISH experiment (Figure 3), which showed the presence of only one fluorescent signal corresponding to the SMARCB1/INI1 gene per cell (Figure 3A). In addition, only one signal corresponding to the control
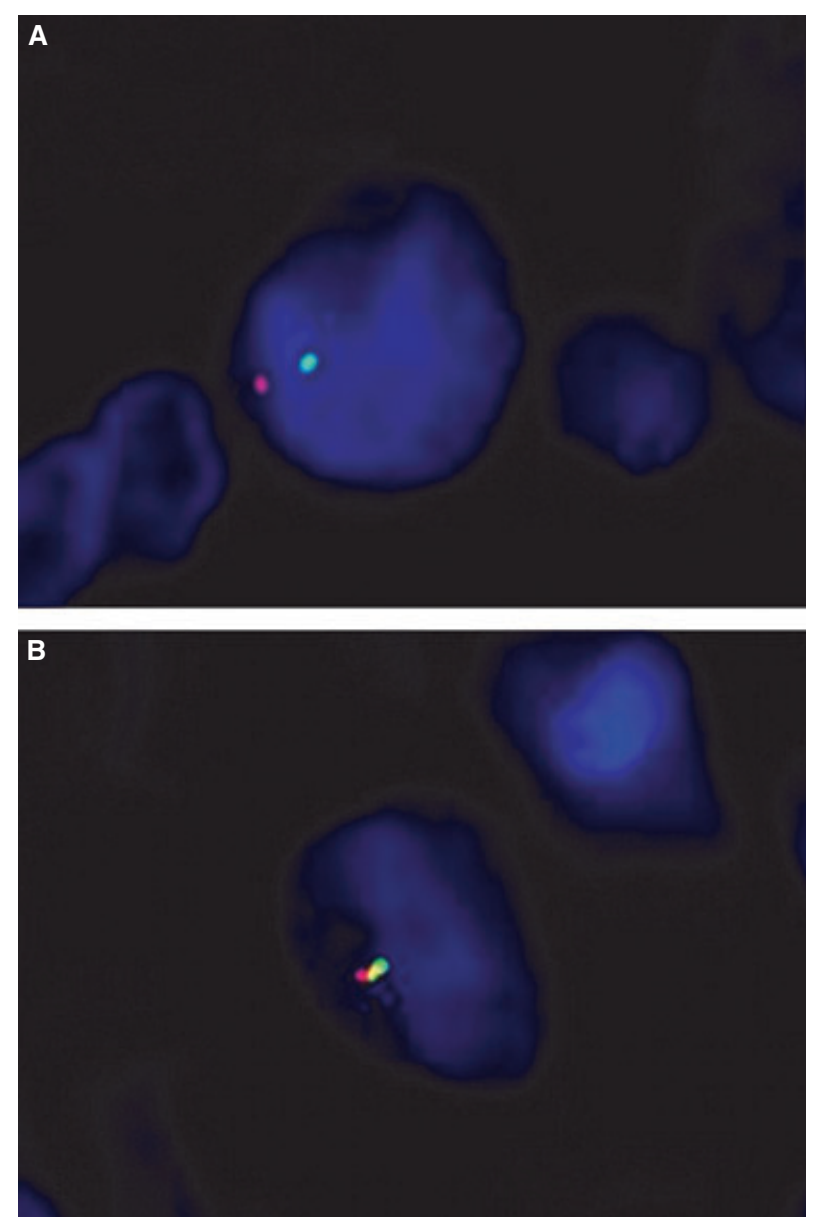

Figure 3. FISH analyses of tumour sections from case 1 using the BAC probe RP11-71G19 containing the SMARCB1/INI1 gene (green signal) and control BAC probe RP11-262A13 located at 22q11.32 (red signal) (A), and a two-colour break-apart probe for EWSR1 gene at 22q12.2 (B). For each probe, only one fluorescent signal is observed (instead of two for normal cells), indicating a loss of SMARCB1 / INI1 as well as of other regions of the long arm of chromosome 22. locus at 22q13.32, as well as the EWSR1 locus at $22 \mathrm{q} 12$, were observed in most cells, suggesting complete monosomy 22 (Figure 3B). For the second case, the only relevant genomic alteration was the loss of a large part of $22 \mathrm{q}$ encompassing the SMARCB1/INI1 locus. For the two cases, all nine exons of the remaining allele were sequenced with no mutation being found.

\section{Discussion}

RMC is a highly aggressive carcinoma, and most patients present with metastatic disease at diagnosis which resists conventional chemotherapeutic agents and leads virtually always to a lethal outcome. . $^{1,26}$ Loss of SMARCB1/INI1 expression, reported by Cheng et $a{ }^{4}{ }^{4}$ in five RMC cases, is confirmed in six additional tumours in our study; this may therefore serve as a strong diagnostic criterion for RMC, as its sensitivity so far is $100 \%$. Moreover, we found that CDC, the main differential diagnosis of RMC, expressed SMARCB1/INI1 in more than $95 \%$ of the cases (21 of 22 ). These results suggest strongly that RMC and CDC, despite similarities in clinical and pathological features, should be considered different entities.

The molecular mechanisms underlying RMC development are unknown. Previous comparative genomic microarray studies demonstrated no evident chromosomal gains or losses, except in one case that featured loss of chromosome $22 .{ }^{27,28}$ In both cases studied here, we observed SMARCB1/INI1 hemizygous deletions with no mutations on the remaining allele. In other malignancies harbouring loss of SMARCB1/INI1 expression, the molecular alterations are most often bi-allelic ${ }^{10,12,20}$ and thus induce complete loss of this tumour supressor gene. No haploinsufficiency of SMARCB1/INI1 has yet been reported, and if these monoallelic deletions contribute to the loss of SMARCB1/INI1 expression, complete loss could be explained by other molecular mechanisms such as epigenetic silencing acting on the remaining allele. One striking feature is the lack of other major chromosomal imbalances, in addition to the chromosome 22 deletions. This is consistent with the findings of McKenna et al. ${ }^{29}$, who demonstrated that most human rhabdoid tumours also lack genomic amplifications, deletions or rearrangements. These authors suggested that epigenetic changes induced by SMARCB1/INI1 loss may substitute, at least partially, for genomic instability, and contribute to carcinogenesis. $^{29}$

In tumours harbouring SMARCB1/INI1 inactivation, histological rhabdoid features are usually com- 
mon. ${ }^{4}$ Even though the rhabdoid appearance is not a diagnostic feature in RMC, a possible link between SMARCB1/INI1 molecular alterations and the acquisition of a rhabdoid phenotype in RMC could be hypothesized. ${ }^{4}$

So far, SMARCB1/INI1 loss has been reported to induce cell cycle progression in part via down-regulation of p16INK4a and up-regulation of E2F factors and cyclin D1. ${ }^{13,14}$ In RMC, SMARCB1/INI1 loss might be involved in cycle cell progression as we observed nuclear immunohistochemical expression of cyclin D1 in all cases. ALK rearrangement with positive immunohistochemical expression and $A B L$ amplification have been reported in isolated cases. ${ }^{78}$ However, we did not observe $A L K$ expression in our cases.

Identification of SMARCB1/INI1 inactivation may also have implications in clinical management of patients with RMC, who are treated currently with conventional chemotherapeutic agents used in CDC. Our results, and previous studies, suggest that epigenetic modulating agents might be considered in RMC. In recent years there has been growing interest in such treatments. ${ }^{30,31}$ Furchert et al. ${ }^{32}$ have evaluated the cytotoxicity of histone deacetylase inhibitors in malignant rhabdoid tumour cell lines; they observed that all nine agents tested inhibited cell proliferation in a time- and dose-dependent manner, and induced reactivation of pro-apoptotic and growth regulatory genes. These encouraging results warrant further studies to evaluate the efficacy of epigenetic therapy in RMC.

In conclusion, our study widens the spectrum of tumours associated with SMARCB1/INI1 molecular alterations, and suggests strongly that renal RMC should be considered a true entity of renal malignancy, and not only as subtype of CDC. The loss of SMARCB1/INI1 immunohistochemical expression may be required for diagnosis of RMC.

\section{Acknowledgements}

We thank F. Keslair for technical asssistance and P. Modena for kindly providing the SMARCB1 BAC probes used for FISH analysis.

\section{References}

1. Eble JN, Sauter G, Epstein J, Sesterhenn I. Pathology and genetics of tumours of the urinary system and male genital organs. Lyon: International Agency for Research on Cancer, 2004.

2. Hakimi AA, Koi PT, Milhoua PM et al. Renal medullary carcinoma: the Bronx experience. Urology 2007; 70; 878-882.

3. Srigley JR, Delahunt B. Uncommon and recently described renal carcinomas. Mod. Pathol. 2009; 22(Suppl. 2); S2-S23.
4. Cheng JX, Tretiakova M, Gong C et al. Renal medullary carcinoma: rhabdoid features and the absence of INI1 expression as markers of aggressive behavior. Mod. Pathol. 2008; 21; 647652.

5. Srigley JR, Eble JN. Collecting duct carcinoma of kidney. Semin. Diagn. Pathol. 1998; 15; 54-67.

6. Yip D, Steer C, al-Nawab M et al. Collecting duct carcinoma of the kidney associated with the sickle cell trait. Int. J. Clin. Pract. 2001; 55; 415-417.

7. Mariño-Enríquez A, Ou W, Weldon $\mathrm{CB}$ et al. ALK rearrangement in sickle cell trait-associated renal medullary carcinoma. Genes Chromosom. Cancer 2011; 50; 146-153.

8. Simpson L, He X, Pins M et al. Renal medullary carcinoma and ABL gene amplification. J. Urol. 2005; 173; 1883-1888.

9. Swartz MA, Karth J, Schneider DT et al. Renal medullary carcinoma: clinical, pathologic, immunohistochemical, and genetic analysis with pathogenetic implications. Urology 2002; 60; 1083-1089.

10. Roberts CWM, Biegel JA. The role of SMARCB1/INI1 in development of rhabdoid tumor. Cancer Biol. Ther. 2009; 8; $412-416$.

11. Roberts CW, Galusha SA, McMenamin ME et al. Haploinsufficiency of Snf5 (integrase interactor 1) predisposes to malignant rhabdoid tumors in mice. Proc. Natl Acad. Sci. USA 2000; 97; 13796-13800.

12. Rousseau-Merck MF, Versteege I, Legrand I et al. hSNF5/INI1 inactivation is mainly associated with homozygous deletions and mitotic recombinations in rhabdoid tumors. Cancer Res. 1999; 59; 3152-3156.

13. Chai J, Charboneau AL, Betz BL et al. Loss of the hSNF5 gene concomitantly inactivates p21CIP/WAF1 and p16INK4a activity associated with replicative senescence in A204 rhabdoid tumor cells. Cancer Res. 2005; 65; 10192-10198.

14. Betz BL, Strobeck MW, Reisman DN et al. Re-expression of hSNF 5 / INI1 / BAF47 in pediatric tumor cells leads to G1 arrest associated with induction of p16ink4a and activation of RB. Oncogene 2002; 21; 5193-5203.

15. Bourdeaut F, Fréneaux P, Thuille B et al. hSNF5/INI1-deficient tumours and rhabdoid tumours are convergent but not fully overlapping entities. J. Pathol. 2007; 211; 323-330.

16. Bourdeaut F, Dufour C, Delattre O. [Rhadboid tumours: hSNF / INI1 deficient cancers of early childhood with aggressive behaviour]. Bull. Cancer 2010; 97; 37-45.

17. Chbani L, Guillou L, Terrier P et al. Epithelioid sarcoma: a clinicopathologic and immunohistochemical analysis of 106 cases from the French Sarcoma Group. Am. J. Clin. Pathol. 2009; $131 ; 222-227$.

18. Modena P, Lualdi E, Facchinetti F et al. SMARCB1/INI1 tumor suppressor gene is frequently inactivated in epithelioid sarcomas. Cancer Res. 2005; 65; 4012-4019.

19. Sévenet N, Lellouch-Tubiana A, Schofield D et al. Spectrum of hSNF5/INI1 somatic mutations in human cancer and genotype-phenotype correlations. Hum. Mol. Genet. 1999; 8; 2359 2368.

20. Versteege I, Sévenet N, Lange J et al. Truncating mutations of hSNF 5 / INI1 in aggressive paediatric cancer. Nature 1998; 394; 203-206.

21. Bourdeaut F, Lequin D, Brugières L et al. Frequent hSNF5/INI1 germline mutations in patients with rhabdoid tumor. Clin. Cancer Res. 2011; 17; 31-38.

22. Sévenet N, Sheridan E, Amram D et al. Constitutional mutations of the hSNF5 / INI1 gene predispose to a variety of cancers. Am. J. Hum. Genet. 1999; 65; 1342-1348. 
23. Reisman D, Glaros S, Thompson EA. The SWI/SNF complex and cancer. Oncogene 2009; 28; 1653-1668.

24. Kohashi K, Izumi T, Oda Y et al. Infrequent SMARCB1/INI1 gene alteration in epithelioid sarcoma: a useful tool in distinguishing epithelioid sarcoma from malignant rhabdoid tumor. Hum. Pathol. 2009; 40; 349-355.

25. Flucke U, Slootweg PJ, Mentzel T et al. Re: Infrequent SMARCB1/INI1 gene alteration in epithelioid sarcoma: a useful tool in distinguishing epithelioid sarcoma from malignant rhabdoid tumor: direct evidence of mutational inactivation of SMARCB1 / INI1 in epithelioid sarcoma. Hum. Pathol. 2009; 40; 13611362; author reply 1362-1364.

26. Watanabe IC, Billis A, Guimarães MS et al. Renal medullary carcinoma: report of seven cases from Brazil. Mod. Pathol. 2007; 20; 914-920.

27. Schaeffer EM, Guzzo TJ, Furge KA et al. Renal medullary carcinoma: molecular, pathological and clinical evidence for treatment with topoisomerase-inhibiting therapy. BJU Int. 2010; 106; 62-65.

28. Yang XJ, Sugimura J, Tretiakova MS et al. Gene expression profiling of renal medullary carcinoma: potential clinical relevance. Cancer 2004; 100; 976-985.

29. McKenna ES, Sansam CG, Cho Y et al. Loss of the epigenetic tumor suppressor SNF5 leads to cancer without genomic instability. Mol. Cell. Biol. 2008; 28; 6223-6233.

30. Melnick AM, Adelson K, Licht JD. The theoretical basis of transcriptional therapy of cancer: can it be put into practice? J. Clin. Oncol. 2005; 23; 3957-3970.

31. Bhalla KN. Epigenetic and chromatin modifiers as targeted therapy of hematologic malignancies. J. Clin. Oncol. 2005; 23; 3971-3993.

32. Furchert SE, Lanvers-Kaminsky C, Juürgens H et al. Inhibitors of histone deacetylases as potential therapeutic tools for high-risk embryonal tumors of the nervous system of childhood. Int. J. Cancer 2007; 120; 1787-1794. 